\title{
SYNTHESIS OF COPPER NANOPARTICLES USING ASCORBIC ACID AND CETYL TRIMETHYL AMMONIUM BROMIDE
}

\section{SAURABH SINGH ${ }^{1}$, BIMLESH KUMAR ${ }^{2}$, NARENDRA KUMAR PANDEY², BARINDER KAUR ${ }^{2}$, ARUN KUMAR ${ }^{2}$, DILEEP SINGH BAGHEL ${ }^{1}$, MALTI G. CHAUHAN ${ }^{3}$, SACHIN KUMAR SINGH ${ }^{2 *}$}

${ }^{1}$ Department of Ayurvedic Pharmacy, School of Pharmaceutical Sciences, Lovely Professional University, Phagwara - 144 411, Punjab,

India. ${ }^{2}$ Department of Pharmacy, School of Pharmaceutical Sciences, Lovely Professional University, Phagwara - 144 411, Punjab, India. ${ }^{3}$ Member Ayurvedic Pharmacopoeia Committee, Pharmacopoeia Commission for Indian Medicine and Homoeopathy Ghaziabad Government of India, Uttar Pradesh, India. Email: Singhsachin23@gmail.com

Received: 28 February 2018, Revised and Accepted: 16 March 2018

ABSTRACT

Objective: The present study highlights the development of a method to synthesize copper nanoparticles (CuNPs).

Methods: CuNPs were developed using $0.01 \mathrm{M}$ copper penta sulfate and $0.11 \mathrm{M}$ of ascorbic acid (AA) and $0.03 \mathrm{M}$ of cetyl trimethyl ammonium bromide solution. The synthesized CuNPs were differentiated through filtration and washed by water (deionized). CuNPs were kept in dialysis bag $70 \mathrm{KD}$ in a $250 \mathrm{~mL}$ glass beaker along with distilled water. The assembly was kept on a magnetic stirrer for $24 \mathrm{~h}$ at $500 \mathrm{rpm}$. Then, the dialysis bag containing CuNPs solution was filtered by a filter assembly with $0.2 \mu$ m nylon filter. The filtered CuNPs were spray dried with the help of spray drier.

Results: The prepared CuNPs were found to be $440 \mathrm{~nm}$ with zeta potential of $-10 \mathrm{mV}$ and polydispersity index 0.314 .

Conclusion: The investigation deciphers the promising and material technique to synthesis of CuNPs by methods for synthetic reduction utilizing strategy using AA (0.2 M) and sodium hydroxide (1 M), and Syloid 244FP.

Keywords: Copper nanoparticles, Cetyl trimethyl ammonium bromide, Ascorbic acid, Spray drying: Particle Size, Zeta potential.

(C) 2018 The Authors. Published by Innovare Academic Sciences Pvt Ltd. This is an open access article under the CC BY license (http://creativecommons. org/licenses/by/4. 0/) DOI: http://dx.doi.org/10.22159/ajpcr.2018.v11is.28531

\section{INTRODUCTION}

Copper nanoparticles (CuNPs) are unique due to their important characteristics such as high thermal conductivity and wide range of therapeutic applications in traditional and modern medicines. CuNPs also have increased surface area to volume ratio, with cost of production. CuNPs have wide therapeutic potential such as antibiotic, antimicrobial, and antifungal when compared with other metals. The major problem occurs during their preparation and preservation. CuNPs oxidized immediately in contact of air. To overcome this problem, reduction or capping is done or different inert media (e.g. argon and nitrogen) are used [1-3]. However, reduction and capping are costly and having poisonous impacts.

CuNPs blending is done by physical or chemical methods. Main physical procedure includes pulsed laser removal [4], vacuum vapor testimony [5], and pulsed wire release [6] and mechanical processing [7]. Chemical procedure includes chemical reduction [8], microemulsion methods [9], sonochemical [10], electrochemical [11], microwave helped [12], and aqueous [13]. Natural or biosynthesis [14] strategies are moreover considered as chemical strategies. CuNPs have high thermal conductivity [15] and with low cost of production as compared to noble metals.

Through chemically reduction method, excellent CuNPs are produced, but hazardous reducing agents are used [16]. Ascorbic acid (AA) works as reducing and protecting agent [15]; therefore, to overcome this problem, AA is used to get harmless CuNPs in the present work.

\section{METHODS}

Chemicals utilized in the various experimental methods were analytical grade. Copper sulfate pentahydrate (CSP) $(0.1 \mathrm{M}), \mathrm{AA}(0.2 \mathrm{M})$ and sodium hydroxide $(\mathrm{NaOH})(1 \mathrm{M})$, Syloid 244FP gifted by W.R. Grace, sodium lauryl sulfate, and deionized water were utilized during experimental methods.

Procedure for preparation of 0.01 Molar CSP

Copper sulfate pentahydrate $0.2496 \mathrm{~g}$ was dissolved in $100 \mathrm{~mL}$ of distilled water to get a concentration of $0.01 \mathrm{M}$.

\section{Procedure for preparation of 0.11 Molar AA}

In order to prepare $0.11 \mathrm{M}$ AA solution, $19.37 \mathrm{~g}$ of AA was dissolved in $100 \mathrm{~mL}$ of water.

Procedure for preparation of cetyl triethyl ammonium bromide (CTAB) 0.03 molar

Cetyl triethyl ammonium bromide (1.093 g) was accurately weighed and dissolved in $100 \mathrm{~mL}$ of distilled water to get a concentration of $0.03 \mathrm{M}$.

\section{Synthesis of $\mathrm{Cu}$ nanoparticles}

In the present study, $0.01 \mathrm{M} \mathrm{CSP}$ and $0.11 \mathrm{M}$ of AA were dissolved in $100 \mathrm{~mL}$ of deionized water in $250 \mathrm{~mL}$ flat-bottom flask equipped with hot plate, a small magnetic stir bar, and a thermometer. The $0.03 \mathrm{M}$ of CTAB was introduced into the solution with rapid stirring at room temperature. Aqueous $\mathrm{NaOH}$ was employed to control $\mathrm{pH}$ 6.5. Before starting the reactions, the $\mathrm{pH}$ of reaction mixture of all three chemicals was monitored by handy $\mathrm{pH}$ meter, and then during the reaction, it was monitored by $\mathrm{pH}$ strip (broad range [pH 2-10] strip was used; the medium dark green color was observed on $\mathrm{pH}$ strip). The mixture was agitated at $85^{\circ} \mathrm{C}$ without any inert gas protection. The temperature was monitored with thermometers. During process, the blue colored mixture turned into brick red, then reddish represented in Fig. 1. CuNPs were separated by filtration and washed with deionized water 

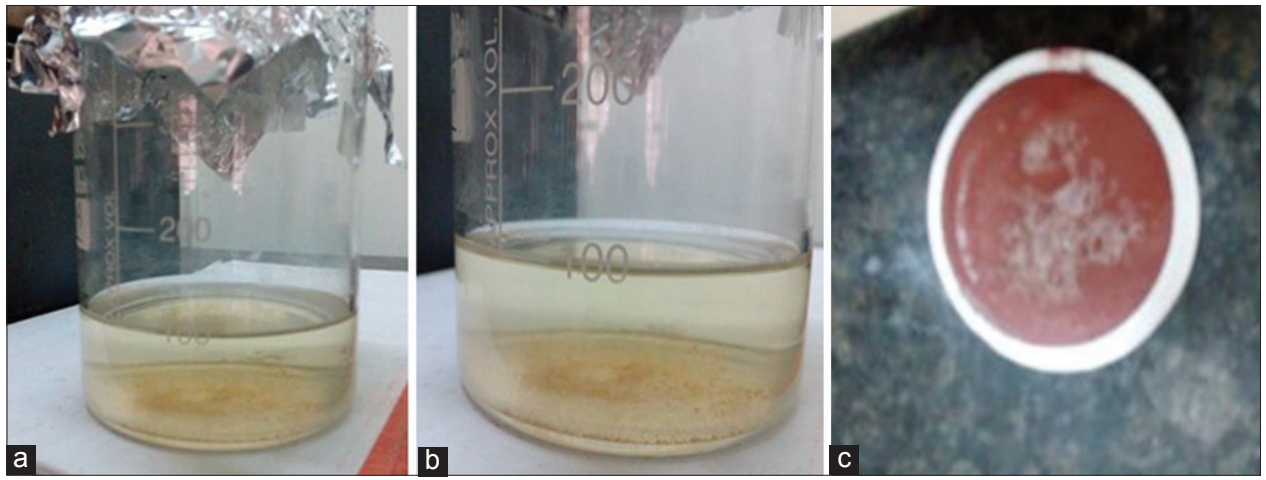

Fig. 1: Steps involved in preparation of copper nanoparticles (a) stage-1 (b) stage -2 (c) stage -3

Table 1: Formula for synthesis of CuNPs

\begin{tabular}{lll}
\hline S. No & Name of Ingredients & Quantity (mg) \\
\hline 1 & Syloid & 500.00 \\
2 & CuSO $_{4}$ & 0.2496 \\
3 & CTAB & 0.0624 \\
4 & AA & 4000 \\
5 & SLS & 225 \\
\hline
\end{tabular}

CuNPs: Copper nanoparticles, CTAB: Cetyl triethyl ammonium bromide, AA: Ascorbic acid, SLS: Sodium lauryl sulfate

Table 2: Batches prepared by design expert software

\begin{tabular}{|c|c|c|c|c|}
\hline Batches & Syloid (g) & SLS (g) & $\begin{array}{l}\text { Feed } \\
\text { rate (min.) }\end{array}$ & $\begin{array}{l}\text { Inlet air } \\
\text { temperature }{ }^{\circ} \mathrm{C}\end{array}$ \\
\hline 1 & 2 & 0.15 & 18 & 120 \\
\hline 2 & 1 & 0.15 & 18 & 130 \\
\hline 3 & 3 & 0.15 & 16 & 120 \\
\hline 4 & 1 & 0.15 & 18 & 110 \\
\hline 5 & 2 & 0.225 & 16 & 120 \\
\hline 6 & 2 & 0.225 & 20 & 120 \\
\hline 7 & 2 & 0.15 & 16 & 130 \\
\hline 8 & 1 & 0.15 & 20 & 120 \\
\hline 9 & 3 & 0.15 & 18 & 110 \\
\hline 10 & 2 & 0.15 & 18 & 120 \\
\hline 11 & 2 & 0.075 & 20 & 120 \\
\hline 12 & 1 & 0.075 & 18 & 120 \\
\hline 13 & 2 & 0.15 & 18 & 120 \\
\hline 14 & 2 & 0.15 & 16 & 110 \\
\hline 15 & 3 & 0.075 & 18 & 120 \\
\hline 16 & 3 & 0.225 & 18 & 120 \\
\hline 17 & 3 & 0.15 & 18 & 130 \\
\hline 18 & 1 & 0.15 & 16 & 120 \\
\hline 19 & 2 & 0.225 & 18 & 110 \\
\hline 20 & 2 & 0.15 & 20 & 110 \\
\hline 21 & 2 & 0.075 & 16 & 120 \\
\hline 22 & 3 & 0.15 & 20 & 120 \\
\hline 23 & 2 & 0.075 & 18 & 110 \\
\hline 24 & 2 & 0.15 & 20 & 130 \\
\hline 25 & 2 & 0.15 & 18 & 120 \\
\hline 26 & 2 & 0.075 & 18 & 130 \\
\hline 27 & 2 & 0.225 & 18 & 130 \\
\hline 28 & 2 & 0.15 & 18 & 120 \\
\hline 29 & 1 & 0.225 & 18 & 120 \\
\hline
\end{tabular}

SLS: Sodium lauryl sulfate

and ethanol. CuNPs were kept in dialysis bag $70 \mathrm{KD}$ (Fig. 2) in a $250 \mathrm{ml}$ glass beaker with distilled water. The assembly was kept on a magnetic stirrer for $24 \mathrm{~h}$ at $500 \mathrm{rpm}$. Then, the dialysis bag contains CuNPs solution was filtered by a filter assembly with $0.2 \mu \mathrm{m}$ nylon.

\section{Preparation of nanoparticles using spray drier}

The obtained CuNPs were found sticky and hence considered as nonstable form. To remove their stickiness, the nanoparticles were adsorbed

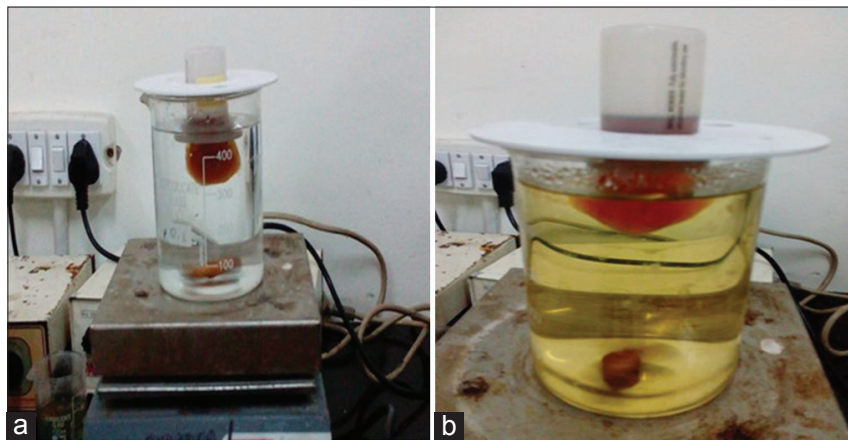

Fig. 2: Filtration of copper nanoparticles by dialysis. (a) Initial stage, (B) after $24 \mathrm{~h}$

on the surface of Syloid 244FP silica and spray dried. The procedure for adsorption and spray drying is discussed below. The initial composition of one batch shown in Table 1. In the suspension of CuNPs, accurately weighed amount of Syloid 244FP was added. The dispersion was stirred for $15 \mathrm{~min}$ and subjected for spray drying using spray dryer - spray mate JISL, Mumbai, India. A total of 29 batches were prepared (F1-F29) as shown in Table 2 by varying the formula composition and operating conditions of spray drier. The study was carried out at three different levels, low, medium, and high.

It was observed that feed rate and inlet air temperature have played a significant role on the particle size and hygroscopicity of CuNPs.

\section{Particle size and zeta potential analysis [16-18]}

Particle size, polydispersity index (PDI), and zeta potential were determined using Malvern Zetasizer Nano ZS90 (Malvern Instruments Ltd., UK) with a $50 \mathrm{mV}$ laser at a fixed angle of $90^{\circ}$. Estimations were completed at $25^{\circ} \mathrm{C}$ utilizing dispensable polystyrene cells and disposable plain folded capillary cells after serial dilutions.

\section{RESULTS AND DISCUSSION}

The CuNPs were analyzed by laser diffraction analysis using Malvern Zetasizer ZS200. Each sample was measured 3 times and mean data were recorded for particle size. The particle size of CuNPs was found to be $440 \mathrm{~nm}$ with a PDI of 0.314 . A value of PDI $<0.500$ indicates very good distribution of particle size. The zeta potential of CuNPs was $-10 \mathrm{mV}$. However, obtained nanoparticles were found sticky. Hence, spray drying was used with suitable adsorbent like Syloid 244FP. After solidification, the flow got increased as found through angle of repose experiment. The initial flow of copper powder was $55^{\circ}$, and after solidification, the angle of repose got reduced to $38^{\circ}$.

\section{CONCLUSION}

The investigation deciphers the promising and material technique to the synthesis of CuNPs by methods for synthetic reduction utilizing 
strategy by utilizing AA $(0.2 \mathrm{M})$ and $\mathrm{NaOH}(1 \mathrm{M})$, and Syloid 244FP. The obtained CuNPs were having particle size of $440 \mathrm{~nm}$ and PDI 0.314. Solidification of obtained CuNPs using spray drier and porous adsorbent like Syloid 244FP enhances the flow of CuNPs. Hence, this synthesis pathway is suitable for the synthesis of $\mathrm{Cu}$ attributed to its simple process and low cost.

\section{REFERENCES}

1. Feldheim DL, Foss JR. Metal Nanoparticles; Synthesis, Characterization, and Applications. New York, USA: Marcel Dekker Incorporated; 2002.

2. Siegel RW, Hu E, Roco MC. Nanostructure science and technology: $\mathrm{R}$ and $\mathrm{D}$ status and trends in nanoparticles, nanostructured materials, and nanodevices. $1^{\text {st }}$ ed. Dordrecht, Netherland: Springer, Academic Press; 1999.

3. Vutpala S, Abbaraju KS. Preparation and characterization of ibuprofen loaded polymeric nanoparticles by solvent evaporation technique. Int $\mathrm{J}$ Pharm Sci 2014;6:416-21.

4. Yeh MS, Yang YS, Lee YP. Formation and characteristics of cu colloids from Cuo powder by laser irradiation in 2-propanol. j Phys Chem 1999;103:6851-7.

5. Liu Z, Bando Y. A novel method for preparing copper nanorods and nanowires. $A d v$ Mater 2003;15:303-5.

6. Available from: https://www.doi.org/10.1063/1.115011. [Last accessed on 2017 May 03].

7. Oleszaka D, Paul HS. Nanocrystalline metals prepared by low energy ball milling. J Appl Phys 1996;79:2976-9.

8. Wang Y, Chen P, Liu M. Synthesis of well-defined copper nanocubes by a one-pot solution process. Nanotechnology 2006;17:6000-6.

9. Pileni MP. Reverse micelles as micro reactors. J Phys Chem 1993;
97:6961-73.

10. Kumar RV, Mastai Y, Gedankan A. Sonochemical synthesis of amorphous $\mathrm{Cu}$ and nanocrystalline $\mathrm{Cu}_{2} \mathrm{O}$ embedded in a polyaniline matrix. Chem Mater 2000;12:3892-5.

11. Molares ME, Buschmann V, Dobrev D. Single-crystalline copper nanowires produced by electrochemical deposition in polymeric ion track membranes. Adv Mater 2001;13:62-5.

12. Available from: https://www.ars.usda.gov/research/publications/ publication/?seqNo115=132674. [Last accessed on 2017 Jul 06].

13. Chu LY, Zhuo Y, Dong L. Controlled synthesis of various hollow $\mathrm{Cu}$ nano/microstructures via a novel reduction route. Adv Funct Mater 2007; 17:933-8

14. Bali R, Razak, N, Lumb A. Synthesis of metal nanoparticles inside live plants. In: International Conference on Nanoscience and Nanotechnology; 2006. p. 224-7.

15. Available from: https://www.worldscientific.com/doi/abs/10.1142/ S1793292012300058. [Last accessed on 2017 Sep 20].

16. Saranyaadevi K, Subha V, Ravindran RS, Renganathan S. Green synthesis and characterization of silver nanoparticle using leaf extract of Capparis zeylanica. Asian J Clin Res 2014;7:44-8.

17. Fatma S, Kalainila P, Ravindran E. Renganathan green synthesis of copper nanoparticle from Passiflora foetida leaf extract and its antibacterial activity. Asian J Phys Clin Res 2017;10:80-3

18. Kumar B, Garg V, Singh S, Pandey NK, Bhatia A, Prakash T, et al. Impact of spray drying over conventional surface adsorption technique for improvement in micromeritics and biopharmaceutical characteristics of self-nanoemulsifying powder loaded with two lipophilic as well as gastrointestinal labile drug. Powder Technol 2018;326:424-2 